3 Ryzen E, Martodam RR, Troxtell M, et al. Intravenous etidronate in the management of malignant hypercalcaemia. Arch Intern Med 1985; 145:449-52.

+ Kanis JA, Urwin GH, Gray RES, et al. Effects of intravenou etidronate disodium on skeletal and calcium metabolism. Am f. Med 1987;82 (suppl 2A):55-70)

5 Ralston, SH, Fogelman I, Gardner MD), Dryburgh FJ, Cowan RA, Boyle IT. Hypercalcaemia of malignancy: evidence for non-parathyroid humoral agent with an effect on renal tubular handling of calcium. Clin Sci 1984;66:187-91.

6 Heller SR, Hosking DJ. Renal handling of calcium and sodium in metastatic and non-metastatic malignancy. $\mathrm{Br} \mathrm{Med} \mathcal{J}$ 1986;292:583-6.

7 Ralston SH, Foelman I, Gardner MD, Boyle IT. Relative contribution of humoral and metastatic factors to the pathoenesis of hypercalcaemia in malignancy. $\mathrm{Br}$ Med $\mathcal{F}$ 1984;288: 405-8.

8 Ralston SH, Boyce BF, Cowan RA, Gardner MD, Fraser WD Boyle IT. Contrasting mechanisms of hypercalcemia in patients with early and advanced humoral hypercalcaemia of malignancy. $\mathcal{F}$ Bone Min Res 1989;4:103-11.

$9 \mathrm{Kemp} \mathrm{BE}$, Moseley JM, Rodda CP, et al. Parathyroid hormone related protein of malignancy: active synthetic fragments. Science 1988;237:1568-70.

10 Bonjour JP, Phillipe J, Guelpa G, et al. Bone and rena components in hypercalcaemia of malignancy and response to a single infusion of clodronate. Bone 1988;9:123-30.

11 Sleeboom HP, Bijver OLM, Van Oosterom AT, Gleed JH, 'Pom HP, Bijoet OLM, Van Oosterom AT, Gleed JH, 'Riordan JLA. Comparison of intravenous (3-amino-1 hydroxypropylidene)-1, 1-bisphosphonate and volume repletion in

12 Ralston SH, Alzald AA, Gallacher SJ, Gardner MD, Cowan RA, Boyle IT. Clinical experience with aminohydroxy propylidene bisphosphonate in the management of cancerassociated hypercalcaemia. $Q \mathcal{J}$ Med 1988:258:825-34

13 Ralston SH, Alzaid AA, Gardner MD, Boyle IT. Treatment of cancer-associated hypercalcaemia with combined aminohydroxypropylidene diphosphonate and calcitonin. $\mathrm{Br} \mathrm{Med}$ $1986 ; 292: 1549-50$.

14 Ringerberg QS. Ritch PS. Efficacy of oral administration of etidronate disodium in maintaining normal serum calcium levels in previously hypercalcaemic cancer patients. Clin Ther 1987:9:1-7.

\section{Prevalence and diagnosis of chronic respiratory symptoms}

SIR,-Dr Peter Littlejohns and colleagues have reported a reduced prevalence of disability associated with chronic respiratory symptoms among patients in south west London compared with that in 1961.' The extent to which prevalence was reduced was, however, fairly small and in women was probably not significant $(2 \cdot 5 \% \mathrm{com}$ pared with $3 \%$ in 1961). The analysis did not take into account non-pulmonary causes of disabling breathlessness, including excess weight and "silent" ischaemic heart disease, so that the true prevalence of respiratory disability cannot be deduced from these findings. In conjunction with the national mortality and morbidity statistics D Littlejohns and colleagues interpreted the position as improving, but this may be wishful thinking.

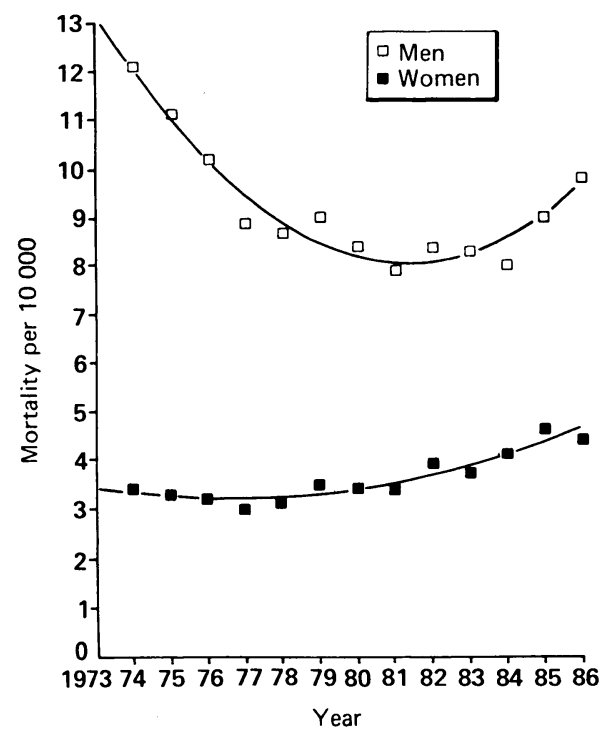

Mortality in patients with chronic bronchitis, emphy'sema, asthma, and chronic airflow obstruction per 10000 population aged 55-64, 1973-86
Among women aged 55-64 mortality in diseases associated with airflow limitation has increased over the past few years, and there seems to be an upward trend among men (figure). The position has deteriorated since 1981 , when a report of the Royal College of Physicians made recommendations for management of what is mainly a preventable condition. ${ }^{3}$ Unfortunately, a high proportion of the patients in greatest need do not receive specialist advice, and their treatment commonly leaves much to be desired. ${ }^{+}$In addition, Dr Littlejohn and colleagues' study showed a high proportion of undiagnosed cases.

As a profession we are having only limited success in treating this type of patient; we need to do more to bring such patients to treatment and to curb smoking, which remains the principal cause of their disability.

chool of Health Care Sciences,

JE COTES

Medical School,

Newcastle upon Tyne NE2 $4 \mathrm{HH}$

Littlejohns P. Ebrahim S, Anderson R. Prevalence and diagnosis of chronic respiratory symptoms in adults. Br.Med f 1989;298. 1556-60. 10 June.

2 Office of Population Censuses and Surveys. Registrar general's annual mortality statstics 1986 and preziously. HMSO: London,

3 Committe on Thoracic Medicine. Disubling chest disease: prevention and care. London: Royal College of Physicians, 1981.

+ Pearce SJ, Posner V, Robinson AJ, Barton JR, Cotes JE. "Invalidity" due to chronic bronchitis and emphysema: how real is it? Thorax 1985;40:828-31.

\section{Non-ionic versus ionic contrast media}

SIR,-Minerva,' relying on the work of Eyes and Goldman, ${ }^{2}$ asks why any patient undergoing urography should be exposed to the risks of the old method of urography using ionic contrast media.

Eyes and Goldman argue that by using a half dose of non-ionic contrast medium the cost is reduced by a half and the urogram is subjectively acceptable, but their work ${ }^{3}$ has been criticised ${ }^{+}$and other authors studying longer series have found no reason to prefer non-ionic media'; sodium salts gave a slightly better urogram than non-ionic media. ${ }^{\circ}$ Non-ionic low osmolar media are supposed to be safer than ionic media but this has yet to be established by clinical trial. Indeed one trial has shown a greater number of delayed reactions to iopamidol than to iothalamate (Conray 320).

Low osmolar media are so expensive (even in half doses) that they have been termed "liquid gold" "and the cost of saving a life given reasonable assumptions is estimated at $£ 500000$ to $£ 1 \mathrm{~m}$, about 10 times the amount the NHS can afford for proved treatments with known effects." The concept of risk factors for predicting reactions to contrast media is seriously flawed as the incidence of important reactions, even in patients with so called risk factors, is extremely low ${ }^{7}$ and the relevance of most of them has not been tested in controlled trials. Nevertheless, up to one half of patients have such risk factors. ${ }^{11}$

The answer to Minerva's question is that low osmolar media are very expensive; though they are more comfortable for the patient, it has not been satisfactorily shown that they are safer in clinical use, and a technically better urogram results from using sodium salts of ionic media.

PETER DAVIES

City Hospital

Nottingham N(i5 IlPB

1 Minerva. Views. Br.Med 7 1989:298:1534. (3 June.)

2 Eves $B$, (joldman $M$. Low dose osmolar intavenous urography. Clin Radiol 1989;40:325.

3 Exes B, Cioldman M. Nixon TE, Scully J, Brown A. Low dose low osmolar intravenous urography. (Clin Radiol 1987;38: $403-8$

+ Davies P'. Low osmolar contract media. C.lin Radiol 1988;39:101
5 Dalla-Palma LD, Rossi M, Stacal F, Agostini R. Iopamidol in urography. A comparison between ionic and non-ionic contrast media in patients with normal and impaired renal function. Urological Radiologv 1982;4:1-3.

6 Davies P, Panto PN, Buckley J, Richardson RE. The old and new: a study of five contrast media for urography. $\mathrm{Br} \mathcal{J}$ Radiol 1985;58:593-7.

7 McCullough M, Davies P, Richardson RE. A longer trial of intravenous Conray 325 and Niopam 300 to assess immediate and delayed reactions. Brf Radiol 1989;62:260-5.

8 White RI, Halden WJ. Liquid gold: low osmolality contrast media. Radiology 1986;159:559-60.

9 Grainger R. Low osmolar contrast media. Br. Med 7 1984;289. 144-8.

10 Wolfe GL. Safer, more expensive iodinated contrast agent: how do we decide. Radiology 1986;159:557-8.

\section{Guidelines on HIV infection}

SIR,-Last year two publications arrived on my doorstep on the same day. The first was a copy of the BMA Guidelines for Doctors on HIV Infection. The second was a copy of New Scientist, which carried the first report that a gene multiplication technique had identified the HIV genome in the blood of a person who was at risk for the disease 36 months before subsequent seroconversion. The guidelines for doctors were based on the stated assumption that the absence of HIV antibodies three months after an accident to a health worker was a reliable indication that infection had not occurred.

It is particularly unfortunate that Dr Jonathan A Shapiro's article, which aims at encouraging a positive attitude towards AIDS in health workers, should reach me alongside another copy of New Scientist, which reports a paper in the New England Fournal of Medicine confirming that silent infection may persist for an uncertain number of years, certainly for more than four. ${ }^{2}$

The BMA booklet is now clearly misleading and should be withdrawn immediately. It seems probable that HIV infection with a small number of virions in an otherwise healthy person usually leads to silent infection. The results of gene multiplication studies in a representative group of health workers are urgently needed.

L M MCEWEN

Allergy Unit,

London Medical Centre,

London WIN IAH

1 Shapiro JA. General practitioners' attitudes towards AIDS and their perceived information needs. Br Med $\mathcal{J}$ 1989;298: 1563-6. (10 June.)

2 Imagawan DT, Lee MA, Wolinsky SM, et al. Human immunodeficiency virus type 1 infection in homosexual men who remain seronegative for prolonged periods. $N \mathrm{Engl} f \mathrm{Med}$ 1989:320:1458-62.

***The secretary writes: “Detection of HIV genetic material by DNA amplification (polymerase chain reaction) was first reported at the Stockholm conference in 1988 after the BMA guidelines had been published. The article in the New England Fournal of Medicine contains several caveats, though reporting positive results with the polymerase chain reaction in three men at up to 35 months before seroconversion and isolation of HIV in 27 in whom seroconversion was not observed at 28-36 months of follow up. The subjects were at high risk of sexual exposure to HIV, in contrast to direct inoculation of HIV, which seems to be more likely to lead to defined seroconversion events. Whether isolation of HIV or positive results by the polymerase chain reaction in the absence of seroconversion implies infection with an HIV strain capable of in vivo replication and pathogenesis has yet to be proved. The results cannot provide an estimate of the proportion of HIV infections that do not stimulate measurable antibody.

"Absolute certainty is rarely possible in medicine, and there is no unequivocal test for absence of HIV infection. We do not judge it necessary to modify our guidance at present. Health workers are not a high risk group for AIDS, and in the rare cases when accidental inoculation leads to HIV infection 